\title{
Попкова Н.В.
}

\section{Философская культура или философская технология?}

Аннотация: В статье рассматриваются сущность философской культуры, причины ее малой востребованности современным массовым сознанием и пути выхода из кризисного положения. Анализируется ситуация с признанием социальной полезности философии в условиях господствующей техногенно-гедонистической рациональности. Сравнивается место философской культуры в рамках культуры классической (в качестве источника основополагающих принципов и понятий) и культуры современной эпохи (когда философия критикуется за бесполезность даже научным сообществом). Исследуется необходимость трансформации философии для современной эпохи. Основные методы исследования, реализованные в работе, - проблематизация, аналогия, методологическая схематизация, рационализация и артикуляция неявных представлений. На примере положения современной науки, перешедшей в стадию технонауки (что означает переход от задачи понимания внешней реальности к задаче ее проектирования, от объяснения - к воспроизведению). Автор рассматривает философию в качестве особой технологии, предназначенной для изменения мира внутреннего, и предлагает развивать философию в направлении, названном технофилософией. Соответственно, каждая философская система рассматривается как совокупность обосновывающих друг друга программ поведения и общения: выделяются основные метафилософские направления, имеющце разные цели исследования, и показывается возможность их истолкования в качестве различных схем автопроектирования личности философа. В результате появляется возможность использовать господство технологически направленного мировоззрения на пользу развития философии, убедительно (для современного менталитета) обосновав ее необходимость для индивида, становящегося личностью. Практическое применение проект технофилософии найдет при переосмыслении этапов развития философии и ее социальных функций, при исследовании неявной или повседневной философии (обыденные представления о жизни, ее цели и ее правилах также являются технологиями).

Ключевые слова: Культура, философия, кризис, наука, технология, технонаука, современность, мировоззрение, рациональность, проектирование.

Review: In her article Popkova examines the essence of philosophical culture, the reason of its small demand by modern mass consciousness and ways of an exit from this crisis. The situation with recognition of social utility of philosophy in the conditions of dominating technology-related and hedonistic rationality is analyzed. The place of philosophical culture within the limits of traditional culture (as a source of basic principles and concepts) and cultures of a modern epoch (when the philosophy is criticized for uselessness even by scientific community) is compared. Necessity of transformation of philosophy for a modern epoch is investigated. The basic methods of research include problematization, analogy, methodological schematization, rationalisation and articulation of implicit representations. As an example, the author discusses the position of modern science which has passed the stage of techno-science (that means transition from a problem of understanding of an external reality to a problem of its designing, from an explanation - to reproduction). The author considers philosophy as the special technology intended for change of the world internal and suggests to develop philosophy in a direction named techno-philosophy. Accordingly, each philosophical system is considered as a set of programs of behavior proving each other and the dialogue: the basic metaphilosophical directions having different research objectives are allocated, and possibility of their interpretation as various schemes of autodesigning of the person of the philosopher is shown. As a result there is a possibility to use domination of technologically directed outlook for the development of philosophy, in modern mentality it has proved necessary for the personal growth of the person. Practical application of techno-philosophy will find the project at reconsideration of stages of development of philosophy and its social functions, at research of implicit or daily philosophy (ordinary representations about a life, its purpose and its rules also are technologies).

Keywords: Culture, philosophy, crisis, science, technology, techno-science, the present, outlook, rationality, designing. 


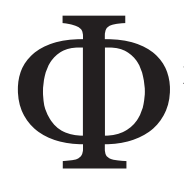
илософия в современную эпоху находится в кризисном положении. Ей снова приходится отстаивать свою автономность: если средние века видели в философии «служанку богословия», то в XX веке не раз предпринимались попытки объявить ее «служанкой естествознания», отнять у философа право самостоятельно исследовать реальность и предоставить ему лишь комментирование истин, добытых методами научного познания. Идут дискуссии о самой возможности сохранения философии как независимой духовной реальности, не совпадающей ни с наукой, ни с религией, ни с искусством. Высказываются различные мнения по вопросу, удастся ли это сделать или философия бесследно растворится в других областях культуры [13, с. 329-346]. Прежняя роль философии как «науки наук», обобщающей научные знания и вводящей их в ценностный контекст, все меньше востребована. Попытки философов формировать новое мировоззрение не встречают в современном мире широкого интереса. Массовое сознание, ищущее не размышлений, а простых ответов на сложные вопросы, не интересуется философскими дискуссиями. Самостоятельно мыслящие люди предпочитают вырабатывать собственные взгляды на мир, в лучшем случае проявляя интерес к философии, но не заимствуя оттуда готовые концепции. Философы в абсолютном большинстве разучились предлагать публике персональный проект, неся за него ответственность. Слишком долго они удобно жили за счет комментариев к принципам, которые другие люди находили и отстаивали, - к принципам религиозным и научным, нравственным и политическим.

Между тем место философии в классической культуре было вполне определенным. Люди, изучая философию, формировали у себя философскую культуру. Что это значит? Во-первых, философски образованный человек защищен от суженности сознания (как известно, именно так специализация и узкая область деятельности может воздействовать на внутренний мир любого специалиста, обедняя и искажая его). Именно философская культура помогает адекватно воспринимать реальное место своей профессии и ее методов на общечеловеческом фоне, а также учит пользоваться ее принципами и допущениями, но не считать их единственно возможными и не «зацикливаться» на одной идее. Во-вторых, при занятиях философией вырабатывается владение навыками критического мышления, что дает возможность сформировать собственное миропонимание, а не стать жертвой обработки сознания, проводимой средствами массовой информации. В-третьих, изучение философии должно преобразовать стихийно сложившиеся мнения в продуманное, обоснованное мировоззрение. И, наконец, философски культурный человек владеет трудным умением жить в заведомо несовершенном мире и не разочаровываться в своих идеалах, видя трудность их воплощения, не изменять своим ценностям под влиянием окружающих. Итак, философия может научить: выдвигать и обосновывать собственные суждения, анализировать и критиковать чужие, отделять существенное от второстепенного, раскрывать взаимосвязи и выявлять противоречия, соотносить факты с идеалами, а значит - видеть действительность в ее развитии. Она необходима для понимания жизни во всей ее полноте и сложности. Но... многие ли люди хотят все это получить? Не поощряется ли сегодня скорее бездумная погоня за удовольствиями?

Что отличает цели, преследуемые философией, от тех целей, которые стоят перед другими областями человеческой практики? Мы должны говорить скорее не о конкретных целях, а о постоянных стремлени$я x$ - о векторе человеческой жизни, направленной на достижение недостижимого. Это различие оправдывает разницу философских путей: каждый человек имеет право выбрать, что именно он желает искать всю сознательную жизнь. Әти цели удалены в бесконечность: по-настоящему преданный своей идее философ никогда не сочтет достаточным имеющееся у него приближение к истине или добродетели. Но зачем такие поиски, если они не приведут к желаемому? А зачем человеку желание жить, если очевидно, что оно однажды станет неисполнимым? Видимо, речь идет об одной из сущностных характеристик человеческой природы - об устремленности в неведомое. У разных людей оно проявляется в различной степени - от интереса к личной жизни знаменитостей до философских размышлений. Поскольку социальные и финансовые дивиденды философия не приносит, а лю- 
ди ей все-таки занимаются, придется сделать вывод: сами по себе философские исследования для некоторых людей являются удовлетворением некоторой потребности.

Какой цели помогает достичь философия? Зачем вообще она нужна людям? Этот вопрос, основанный на требовании пользы и эффективности, показался бы кощунственным для философов классических. С тех пор, как Аристотель назвал философию самой благородной и самой бесполезной из наук, в течение столетий именно неприменимость философских изысканий для презренных практических нужд считалась одним из признаков ее аристократичности, ее превосходства. Но времена меняются - и они поставили полезность на одно из первых мест в списке тех критериев, которым должна соответствовать любая форма человеческой деятельности, чтобы оправдать свое существование. Именно вопрос о пользе философствования, как правило, задается молодежью, приступившей к изучению этой науки. Философы старой закалки могут гневно отвергать подобную профанацию любимой дисциплины, но даже им приходится приводить списки социальных функций философии. После этого скептически настроенные юные умы задают следующий вопрос: а какой из поставленных перед философией в древности вопросов она разрешила к удовлетворению всех философствующих? Где хоть одна философская истина, с которой все, причастные к этому благородному занятию, согласны? Каков смысл в продолжении философских исследований, если философам почти не достается общественного внимания? Пренебрежительные отзывы о бесполезности философии и ни в чем не разбирающихся философах можно слышать со всех сторон - от политиков до, казалось бы, соратников по интеллектуальной работе - представителей естественных наук. Возникает соблазн изменить способ философствования: сделать свои труды более легкими для усвоения, пропагандировать философию в средствах массовой информации (неизбежно подчиняясь их форме изложения, чуть ли не до комиксов), даже ввести уроки философии в школах (видимо, чтобы использовать отголоски некритического детского мышления). Вопрос о полезности философии постоянно задается в современном мире (критерий полезности из области практики перешел на другие формы деятельности) и с ответом связан прогноз будущего философии (в случае ее «бесполезности» - негативный).

Но вопрос «зачем нужна философия» построен согласно иной, технической рациональности - и философ, на него отвечающий, уже принимает правила не своей игры. Само предположение, что явление оправдано своей полезностью, основано на инструментальном понимании окружающего мира, в котором все представляется в виде инструментов, пригодных только для достижения какой-либо цели. Но другие типы рациональности лишены этой односторонности и признают существование многих объектов, существующих «низачем». Зачем нужны Луна и снег, горы и бабочки? Зачем нужны мы сами и наша планета?

Разумеется, философы отвечали и на этот вопрос. Приведем ответы, хронологически нам близкие. Смысл философского исследования, по В. С. Степину, «всегда состоял в том, чтобы не только прояснить те мировоззренческие структуры, которые определяют образ мира... но и предложить возможные варианты новых жизненных смыслов и новых ценностей. Решая эти проблемы, философия выступает, с одной стороны, как критическое осмысление глубинных оснований культуры... а с другой, как проект ее возможных изменений» [20, с. 145]. Философия - это «любовь к мудрости», а не претензия на нее. Философия - «это открытая когнитивная система, реализующая рефлексию над наиболее общими, предельными вопросами бытия и одновременно являющаяся конкретно-практическим размышлением над использованием результатов данной рефлексии в жизни людей», утверждает В. В. Миронов [10, с. 70]. Более того, философия - «интеллектуальная, за-умная (то есть находящаяся за рамками обыденного ума) игра», которая с позиции здравого смысла «часто трактуется как глупость» [11, с. 18]. Современные российские философы видят специфику философии в качестве «наиболее систематизированного, максимально рационализированного мировоззрения своей эпохи» [17, с. 137] (В. В. Соколов) или формы «самосознания культуры, специфического способа осмысления ее духовных оснований» [9, с. 111] (В. А. Кутырёв), через которое «осуществляется индивидуальное обоснование все- 
общих начал мышления» [2, с. 309] (В. С. Библер) и происходит «рациональное осмысление категорий культуры, которые функционируют в обыденном мышлении как неосознанные структуры» [18, с. 55] (В. С. Степин). Различными словами философы говорят примерно одно и то же: тот, кто стремится философствовать, сумеет осмыслить недосказанное и прорваться через общие места и стереотипы к истинному смыслу происходящего. Вместо знаний о внешнем мире философия обещает человеку знания о самом себе; но каждый ли стремится к подобной цели? Обещая бесконечный поиск истины, философия привлекает немногих - и отталкивает массы людей, желающих прежде всего уютного покоя и жесткой системы убеждений. Философия, соглашается А. А. Гусейнов, «прежде всего исследует принципиальные возможности рационального понимания мира». Но этого мало: она учит не только правильно мыслить, но и правильно жить, говоря о «возможностях, пределах и путях» совершенствования мира. Поэтому А. А. Гусейнов определяет философию как «утопию культуры»: понимание мира она доводит до «формулирования программ добродетельной жизни», конструируя «идеальный образ мира и идеальный способ существования в нем». Но в современном мире нет места для утопии - и нет места для философии: она бесплодна. В этом, считает А.А.Гусейнов, и заключается современный кризис философии [6, с. 39-42]. На самом деле философия должна быть этическим проектом «нравственно достойного образа жизни»: не переставая быть мыслью, стать поступком. Философское мышление является «принципиально критическим к наличным формам жизни»: задача философии, по А. А. Гусейнову, - «поддерживать потребность задавать вопросы, нести культуру сомнения» [7, с. 19-20]. Нужно ли все это людям?

Многие видные ученые признавали важность философии для развития науки. Так, В. И. Вернадский показывал, как наука, изымая «из ведения философии вопрос за вопросом», в то же время позволяла ей открывать все новые горизонты [4, с. 217]. По его словам, «источники наиболее важных сторон научного мировоззрения возникли вне области научного мышления, проникли в нее извне»: это и «всеохватывающее ее представление о мировой гармонии, стремление к числу», и понятия атома, материи, энергии, бесконечности... Все эти идеи зародились и развивались в философии [4, c. 206]. Но философия, считал В. И. Вернадский, «никогда не решает загадки мира - она их ищет». В ее основе «всегда лежит сомнение»: за тысячелетия философия «создала могучий человеческий разум» и «основы нашего научного знания», выработала отвлеченные понятия [4, с. 325]. Но сегодня все чаще ученые отзываются о философии пренебрежительно, отмечая ее «непостижимую неэффективность» [3, с. 133] или объявляя об ее смерти [21, с. 9]. Впрочем, пояснив, что философия «не поспевает за современным развитием науки» и поэтому «факел, освещающий наш путь к познанию» перешел из рук философов к ученым, автор этого высказывания С. Хокинг вынужден формулировать собственные философские тезисы, заявляя: «Не имеет смысла спрашивать, реальна или нет модель мира, важно одно: соответствует ли она наблюдениям» [21, с. 53]. Как видим, философия предлагает довольно специфический дискурс, обещая скорее рост неопределенности, нежели ее уменьшение.

Философия иногда называется одной из наук; порою высказывается мнение, что наука и философия являются двумя сторонами единого процесса познания. Если наука идет по пути дифференциации, выделяя для удобства исследования все меньшие части мира и ограждая их все большим количеством допущений, то философия не имеет права забыть ни об одной стороне реальности, должна учитывать абсолютно все, познавая мир в его целостности. Науки решают проблемы и дают человеку законы природы, позволяя повышать уровень удовлетворения его потребностей. Философия подрывает уверенность в «очевидных» вещах и заставляет смотреть на мир нестандартным образом. Если научное познание шло по пути максимальной объективности, всячески исключая особенности конкретного человека из получаемой картины мира, то философия осмысляет мир с субъективной, человеческой точки зрения. Философские идеи, показывает В. С. Степин, часто выполняли эвристическую роль в научном поиске, то есть выступали условием появления новых идей в естествознании. Именно философия разрабатывала катего- 
риальный аппарат и показывала выход за рамки традиционных способов понимания объектов [19, с. 255-259]. Итак, по словам И. Т. Касавина, «наука решает проблемы, которые могут быть решены; философия ставит проблемы, которые не могут быть решены». Философские проблемы, «не имея однозначного и окончательного решения», рассматривается в более широком контексте, нежели научная: философский дискурс порою осуществляет «нелогические, пробные, поисковые шаги, неочевидность и даже абсурдность которых иной раз бросается в глаза» [8, с. 21-23]. Что же происходит с наукой сегодня? Находится ли она в кризисном положении, как и философия, или сумела модернизироваться?

В течение многих столетий для научного дискурса была общепринятой «научно-инженерная» (по словам В. М. Розина) трактовка природы, которая понималась как «объект технического действия и манипулирования», а природные процессы - как то, что можно рассчитать и спрогнозировать, чем можно управлять [16, с. 20]. Чтобы «овладеть природой, управлять ее процессами», ученые стремились представить эти процессы в виде механизмов [14, с. 92-93]. Классическая наука рассматривала природу как «источник скрытых сил и энергий, которыми человек может овладеть, если только... он выявит устройство (законы) природы»; как то, что человек может описать теоретически и воспроизвести технически. Социальным проектом, воплощению которого отдавали свои силы ученые, было «овладение силами природы с целью... установления в мире нового порядка, обеспечивающего человеку почти божественное могущество» [16, с. 242-250]. Но для современной, постнеклассической науки объект исследования - это объект «желательный с точки зрения исторических и социальных изменений». Неудивительно, что ученому придется менять свое видение и мышление, вести работу «по приведению себя в такое состояние, в котором впервые становится возможной эффективная мысль». Социальное действие, направленное на изучаемый постнеклассической наукой объект, с одной стороны, «должно встраиваться в естественные тенденции» его изменения, с другой - «отвечать устремлениям исследователя». Более того, объект исследования «представляет собой проекцию и объ- ективацию сложной системы... дискурсов, практик и властных отношений», поэтому следует изучать его дискурсы (публичные и скрытые) и «сеть властных отношений, определяющих... как практики, так и дискурсы» [15, с. 27-31]. Например, исследуя технику как «условие и один из механизмов социальности», В. М. Розин приходит к выводу, что развитие техники обусловлено «давлением культурных картин реальности»: именно техника выступает основным способом такого подтверждения [15, с. 111]. Культура и социум определяют направления и условия становления новой техники, но не только: часто «новая техника предопределяет на уровне предпосылок становление новой культуры». Культура как социальный организм, считает В. М. Розин, не может существовать без технического воплощения - «без социальных институтов, без хозяйства, без удостоверения своей реальности» [15, с. 134-136]. По словам В. М. Розина, «именно технические сооружения и достижения материально подтверждают культурную реальность, какой бы странной и необычной она ни была» [15, c. 142]. Когда «техника стала концептуализироваться как условие социальности культуры», социальная жизнь стала пониматься как «изучение законов природы (при этом сам человек и общество тоже понимались как природные явления), обнаружение ее практических эффектов, создание в инженерии механизмов и машин, реализующих законы природы, удовлетворение на основе достижений естественных наук и инженерии растущих потребностей человека» [15, c. 164-165]. Даже смысл культурного бытия, отмечает В. М. Розин, «задается сегодня в рамках технической реальности» [15, c. 191]. Подобная перестройка видения объекта характерна и для других областей современной науки. Неудивительно, что для современного типа научной рациональности предлагается понятие «технонаука»: в ней, с одной стороны, «строятся объяснительные схемы природных явлений и формулируются предсказания хода... естественных процессов», а с другой - «конструируются проекты не только новых экспериментальных ситуаций, но и структурные схемы новых, неизвестных в природе и технике систем» [5, с. 113]. Согласно В. Г. Горохову, цель технонауки - не понимание предмета исследования, а его воссоздание; 
она направлена на проектирование. Coзерцательная позиция классической науки сменяется деятельностной парадигмой, а описание независимой реальности - отказом от натуралистического описания мира.

Итак, современная форма существования и развития научного знания была названа технонаукой. Поскольку «техногенная среда превращается из простого приложения научного знания в естественную среду его развития», логично назвать именно так «ставшее неразрывным переплетение собственно исследовательской деятельности с практикой создания и использования современных инновационных технологий» или «взаимосвязанный комплекс стимулирующих друг друга научных практик и технологий» [1, с. 201-202]. В чем же отличие технонауки от науки классической? Традиционное научное отношение к природе включало, по словам А. Л. Андреева, «репрезентацию действительности в виде некоторой воспроизводящей ее сущностные характеристики модели и интервенцию субъекта в эту действительность в форме направляемых при помощи таких моделей практических действий». Считалось, что при этом «предметный мир мог быть воспроизведен в его собственных, объективно ему присущих качествах». Сегодня технонаука рассматривает природу «как огромную совокупность разнообразных хитроумных устройств, предназначенных для выполнения самых разных функций... как склад инструментов и приспособлений, которыми мы можем воспользоваться». В результате «становится возможным реинженеринг природных систем с целью их улучшения» [1, с. 203-204]. Традиционные теоретические модели обладали ясной структурой и заданным набором свойств, а модели технонауки-- это «черные ящики»: мы определяем их поведение при варьировании различных параметров, но не понимаем их устройство. Если классическая наука «овладевала объективной реальностью посредством противопоставляемых ей и отделенных от нее теоретических моделей», то технонаука «делает то де самое, используя одни фрагменты этой реальности вместо других». В результате «задача теоретической репрезентации исследуемых объектов даже в принципе не может быть отделена от материальных условий производства знаний, а стало быть, и от практических интер- венций субъекта познания в материальный мир» [1, с. 204-205]. Таковы характерные черты новой стадии развития науки.

А как может измениться в новом, техногенном обществе философия? Не следует ли ей, сохранив классические культурообразующие черты, дополнить их технологическими возможностями, освоив новые методы и поставив перед собой дополнительные цели?

Если под технологией понимать способы совершенствования человеческой жизни, то философия - одна из технологий. Классическая философия долго рассматривалась как некий логический конвейер, путем логических операций ведущий от предпосылок к выводам - рецептам улучшения внутреннего мира человека. Техника изменяла мир внешний, философия - мир внутренний. Недаром от философов прошлого дошли не только их книги и высказывания, но и случаи из их жизни: словесное устремление к духовной ценности не может существовать отдельно от попыток проявить ее в реальности, поэтому философ, формулируя найденный им путь совершенствования, воплощал его своей жизнью - и его биография была результатом мысленного эксперимента. Возможно, одна из причин кризиса современной философии - то, что философы не решаются ставить перед собой столь глобальные задачи и уходят в частные исследования, превращаясь в обычных, мало интересных внешне людей.

Каждый раз, задавая вопрос, что думает философия о той или иной проблеме, мы получаем несколько ответов, развиваемых разными метафилософскими подходами. Можно выделить четыре основных варианта направленности философских исследований:

a) нужно философствовать, чтобы понимать мир и действовать;

б) нужно философствовать, чтобы понимать людей и сотрудничать;

в) нужно философствовать, чтобы понимать себя и быть человеком;

г) нужно философствовать, чтобы понимать пути мышления и освобождаться от ошибок [12, с. 256-257].

Как видим, философия не лишена некоторой цели, которая (хотя и находится в стороне от целей чисто прагматических) имеет жизненный смысл. В чем общность этих подходов? В том, что последователи 
всех этих метафилософских направлений стремились к пониманию - причем пониманию того, что было недоступно научному познанию (выходя за пределы научных возможностей конкретной эпохи или за пределы научного дискурса в целом).

Тем не менее, различие между техническими и философскими практиками налицо: для технических есть количественная мера оценки - эффективность, а для философских - нет. Среди технологий легко выделить более эффективную, использующую меньше ресурсов или дающую меньше отходов. Как оценивать философские учения? Из предложенных за два с половиной тысячелетия мысленных проектов построения правильной жизни и правильного общества как выбрать верный - особенно если учесть, что реальность постоянно искажала идею? Какую характеристику избрать в качестве критерия для сравнения? Материальный успех последователей данного учения? Но увлеченность духовной стороной жизни часто мешает человеку достигнуть социального и финансового успеха: многие средства построения карьеры противны тому, кто помышляет о самосовершенствовании. Философия, как и любое другое занятие, требует времени, сил и даже жертв: есть занятия и интересы, с нею не совместимые, хотя и прибыльные. Кто сейчас помнит имена политиков и олигархов времен Сократа, Конфуция или Авиценны? Одни получили земной успех - и забыты; другие умерли в нищете, но память о них хранится тысячелетиями, какой жизненный путь считать образцом? Итак, объективного критерия нет. Дело в том, что технические практики начинаются и завершаются в материальном мире, а истоки (и, возможно, плоды) практик философских уходят в иной, идеальный мир. Можно считать его реально существующим высшим миром или отождествлять с совокупностью общечеловеческих культурных ценностей, но как принципы, на которых философские системы были основаны, так и конечные результаты, к которым приводит их реализация, от нас скрыты. Причины возникновения мира, цель исторического процесса, судьба человека - обо всем это мы можем только делать предположения. Строго говоря, все философские теории - воздушные замки: их фундамент скрыт в тумане трансцендентного, и оста- ется неясным, достаточно ли он прочен и есть ли он вообще.

Но принципы философии лежат в основе культуры: на них воздвигнуто здание цивилизации, которое, таким образом, также лишено фундамента - той последней цели, ради которой научно-технический прогресс и реализован. Не эта ли метафизическая беспочвенность современной эпохи отвечает за то, что именно она породила глобальные проблемы? Неудивительно, что широко понятая техника приближается по своему содержанию к философии. Перед нами два вида практик, два их полюса: одна направлена на изменение мира внутреннего, другая - на изменение мира внешнего. Философия побуждает человека быть недовольным собой и изменять себя, техника направляет его внимание на несовершенство природы и предлагает изменять ее. Философия и техника - противоположности и, как полагается противоположностям, в самой полноте своих противоречий находят единство. Основа этого единства - человек, чьи взгляды обращаются то на внутренний мир, то на внешний - и результатом были технические или мировоззренческие революции.

Не следует ли философии, вслед за наукой в целом, усилить свою технологическую направленность (раз уж она востребована в современном мире) и перейти от попыток понять мироздание (которые явно запутались в противоречиях и стали неудачными дубликатами научных исследований) к проектированию... чего? Перестройкой внешнего мира занимаются наука и инженерия; но остается еще мир внутренний. Философия может заняться проектированием самого философа: различные философские системы займут место моделей предлагаемой перестройки! Впрочем, подобной «технологией жизни и смерти» философия была при своем зарождении, гораздо позже перейдя к исключительно практической деятельности. Поэтому новое обличие философии, которое можно назвать технофилософией, является не чем-то абсолютно новым, а раскрытием того потенциала философского дискурса, который последние столетия оставался в забвении. Итак, наука показывает принципы и методы изменения окружающего мира, а философия - самого человека: это автопроектирование.

Развивая технофилософию, мы встретимся с многими незнакомыми аспектами 
традиционных философских проблем. Например, привычное противопоставление философской рефлексии и обыденного мышления придется переосмыслить. Неотрефлектированные, обыденные представления о жизни, ее цели и ее правилах также являются технологиями и имеют с технологиями философскими большее сходство, нежели казалось. Тогда придется анализировать и неявную философию, содержащуюся в традиции, здравом смысле, стереотипах. Философия умолчания, философия повседневности - ее истоки скрыты в прежних философских концепциях, которые были (хотя бы частично) реализованы и утратили свой бунтарский потенциал, свой экспериментальный характер. Также придется показать размытость грани между философией профессиональной и любительской: для технофилософии философом является любой человек, который ищет и реализует собственный жизненный проект.

Можно будет по-новому рассмотреть историю философии, выявив философские революции - точки бифуркации, после которых прежде единое русло философствования распадалось на несколько логически несовместимых жизненных проектов (существующих в обществе одновременно, хотя отдельный человек вынужден выбирать между ними).

Именно технофилософия предстает как форма выживания философии в современных условиях. Каждая философская система будет рассматриваться как совокупность обосновывающих друг друга программ поведения и общения. Сначала она, как индивидуальный жизненный проект, развивается одиночками; потом некоторые системы, попадая в резонанс с назревшей необходимостью прорыва к новым мировоззренческим путям, становятся принципами новой культуры, переходя в область массовых практик. Можно обосновать введение понятия философского риска, которое отразило бы опасность неправильно указанного жизненного пути как результат недостаточно последовательного проведенного философствования. В результате перед создателями технофилософии откроется новое поле исследования.

Как видим, философское исследование умножает количество вопросов: анализируя одну проблему, оно вскрывает десяток новых. Эта особенность, присущая фило- софии с начала ее существования, невыгодно отличает ее от других форм духовного освоения действительности - научной и религиозной, которые уверенно дают ответы (хотя множественность религиозных систем и наличие периодических научных революций показывают, что на самом деле эти ответы не являются окончательными). Но исследование столь сложной проблемы, как плодотворность или гибельность пути развития цивилизации, не может сразу дать простые и верные ответы. Для мыслящего человека многозначность и осторожность философии - скорее свидетельство надежности ее дискурса. Любое направление философских поисков есть по сути поиск себя, нахождение смысла собственной жизни. Поэтому свобода поиска, свобода выбора лежит в основе философствования: оно - непрерывное самопостроение (иногда - болезненный слом старых мыслительных привычек), нужду в котором испытывают далеко не все люди. В отличие от научных и религиозных путей самопознания, философия - частный исследовательский проект: человек прокладывает его на свой страх и риск, идет по нему в одиночку (в лучшем случае - в сопровождении группы духовно близких людей). Стараясь мыслить так, как никто еще не мыслил, и дать новые ответы на вечные вопросы, философ находится постоянно на грани ошибки. Но главная из его ошибок - ограничиться только словами и не воплощать в жизнь практические результаты своих размышлений. Современная философия находится в кризисе, но, как и любой кризис, он может завершиться не только ее деградацией, но и скачком в развитии, подъемом на новую ступень.

\section{Комментарий гл. редактора (Вадима Розина)}

На мой взгляд, статья Натальи Попковой - замечательная, демонстрирующая подлинный философско-культурологический дискурс, который хочется продолжить. Попкова подняла много проблем, каждая из которых нуждается в конкретизации, как говорится «Бог в деталях». Продолжу в плане конкретизации всего по одной линии - проблемы автопроекта, на которою у меня другая точка зрения.

В ситуации постмодерна, в которой мы все находимся, недостаточно просто рас- 
сказать, что мы думаем по поводу той или иной реальности или проблемы, необходимо продемонстрировать, как мы мыслим, какой подход реализуем, когда мыслим. Сюда же относится и наша позиция: с кем мы полемизируем или солидаризируемся. Так вот я выступаю против проектной установки, не вообще, а относительно человека и особенно самого себя. Хотя я себя могу замышлять и пытаться этот замысел в отношении себя реализовать, но получается при этом вовсе проектирование себя, а нечто другое.

То есть замышлять то мы можем, но реализовать свои замыслы - только в тех случаях, когда наша природа им не сопротивляется. Л.С. Выготский, вероятно, с этим бы не согласился. Он, как известно, утверждал, что практической целью психологической практики («психотехники») является «подчинение и овладение психикой». Его концепция психотехники показывает, что помимо проблемы - соотношения личной свободы и необходимости, существует еще одна, а именно, соотношение в личности естественного и искусственного планов. С точки зрения, Выготского все естественное в личности на самом деле - это искусственное, психотехническое.

Отметим общие моменты, характерные почти для всех видов и направлений психотехники, включая и концепцию автопроекта. Во-первых, любая психотехническая работа предполагает ряд, так сказать, психотехнических установок и ценностей: на изменение личности, работу над собой, преодоление себя, изменение своих состояний, переход в эзотерическую реальность и т.п., естественно, специфичные в каждом направлении психотехники. Второй момент - это усилия, направленные на подавление, отказ, снижение значимости и т.п. отрицательные действия в отношении определенных желаний, естественных потенций и устремлений личности, определенных планов ее поведения. Как правило, борьба ведется с теми естественными структурами личности человека, которые не отвечают психотехническим установкам и ценностям, идеалам совершенной личности. Третий момент, в определенном смысле противоположный предыдущему - это культивирование, развитие тех желаний, устремлений, планов личности, которые, напротив, соответствуют психотехниче- ским установкам, ценностям и идеалам. Еще один общий момент, хотя он может проявляться совершенно по-разному, связан с формированием способности произвольно входить в определенные эмоциональные, духовные или психические состояния, начиная от простых чувственных ощущений и восприятий (вызывание у себя ощущений тепла, холода, тяжести, видения определенных цветов, фонов и т.п.) вплоть до сложных переживаний, иногда даже высшего порядка («восприятия» абстрактных идей, образов, сцен, психодрам и т.д.).

Для понимания возможностей психотехники особое значение имеют случаи, когда совершенствование не идет, не получается (человек подавляет в себе определенные желания, а они прорываются снова и снова, он пытается жить правильно, но это не получается). В чем тут дело?

Во-первых, нужно признать, что личность в целом не совпадает с человеком, что личность хотя и важная, но все же часть его психики. Кроме того, личность может пониматься как много разных Я (разных субъектов в одном человеке) : Я идеальное и Я реальное, Я волящее и Я пассивное, несколько Я, реализующих противоположные или просто несовпадающие устремления и планы человека и т.д. Наблюдения показывают, что каждое такое Я нашей личности часто претендует на представительство всей личности в целом (манифестирует личность в целом), что разные Я личности взаимодействуют или даже борются друг с другом, что равновесие или согласие разных наших Я не всегда достижимо.

Но ситуация еще сложнее: помимо личности в человеке действуют и другие начала. Например, телесность (чувство боли, половое чувство, чувство голода или насыщения, физические силы, энергетические потенциалы организма и т.д.), родовая сущность человека (совпадение его с группой, сообществом, культурой), его духовная сущность (человек как воплощение духа и культа). Опять же наблюдения убеждают нас, что личность нередко вступает в конфликт с телесностью (например, подавляет ее; противоположная ситуация - культивирование телесности), что родовая сущность человека может влиять на личность, даже управлять ею (пример, затмение разума на почве религиозных или национальных раздоров), что эгоистическое начало в лично- 
сти может конфликтовать с его духовной сущностью.

Но если это так, если в человеке действуют несколько равноценных сил и начал (разные Я, телесность, родовая и духовная сущности), то можно предположить, что психотехнические устремления и усилия, если они не совпадают с общим движением (развитием) и ориентацией других начал, будут или успешно гаситься или парализоваться. В этом случае, действительно, психотехническая деятельность будет действовать вхолостую, не приведет к каким-либо изменениям в человеке, хотя вполне может обеспечивать компенсаторные функции личности, например, создавать условия для символической реализации устремлений человека к совершенствованию себя.

Если же, напротив, общая ориентация и движение начал и сил человека направлены именно к совершенствованию личности, то в этом случае психотехническая деятельность, направленная на подобное совершенствование, вольется в общий поток изменений, усиливая и поддерживая его. Но это значит, что в данном случае помимо психотехнических целей и усилий человек реализует и другие (личностные, родовые, духовные): он совершенствует свою личность, работает над собой, участвует в жизни общества и культуры. Следовательно, в этом случае психотехническая работа осмысленна и эффективна именно потому, что существует и разворачивается в более широком личностном и культурном контексте. Означает ли сказанное, что человек вообще не может изменить себя и что психотехническая работа ничего не дает? Вероятно, нет, я хотел обратить внимание на другое - насколько этот процесс сложный и негарантированный. Еще одна сторона этой проблемы состоит в том, что для того, чтобы работа в отношении себя стала возможной и реально помогла, человек, вероятно, должен пережить кризис, преодоление которого часто невозможно без внутреннего духовного переворота и помощи других людей.

Но даже если получается реализовать себя в соответствии с замыслом, возникает принципиальный вопрос - проектирование ли наше действие? Вряд ли, скорее так кажется. В своей жизни человек сталкивается с различными экзистенциальными проблемами (ситуациями), которые он пережи- вает и старается разрешить. В результате имеет место «эволюция личности», то есть направленное развитие, постепенно приводящее к экзистенциальному кризису, к невозможности жить по-прежнему. Формой разрешения кризиса выступает экзистенциальный поступок. Необходимое условие - конституирование себя и реальности во вне. Совершая поступок, человек, с одной стороны, себя осознает, то есть уясняет, что для него приемлемо и органично, с другой - конструирует (приписывает себе как личности определенные черты).

Но социальность не сводится только к экзистенциальным ситуациям. Она задается также социальными практиками, в рамках которых человеку вменяются определенные социально значимые представления. К числу таким практик относится: образование, идеология, политика, искусство, наука, а в интересующим нас случае психоанализ и другие психологические практики. Концепция автопроекта - это установка на создание еще одной психологической практики, в рамках которой человек мог бы себя делать по своим замыслам. Но, спрашивается, какой образ личности при этом предполагается? Если иметь в виду проектирование, то личность - это всего лишь техника. Однако я лично за такие социальные практики, которые не превращают человека в технику, а расширяют его сознание, не расщепляют его, а собирают, позволяют действовать реалистично и в тоже самое время нравственно и духовно. Опять же, все это далеко от проектных установок в отношении человека и себя.

К сожалению, современная социальность в обоих ее аспектах (экзистенциальные ситуации и практики) испытывает человека на прочность: расщепляет, лишает нравственности, постоянно ставит в ситуации, где он не может продолжать жить. Но, вероятно, таковы все переходные времена. В результате человек уже не может конституировать себя надолго, напротив, вынужден периодически себя возобновлять.

Что же, в конце концов, следует из моего размышления? Мы не проектировщики себя, а скорее, «путники-сталкеры». Мы себя замышляем, определенным образом концептуализируем, и пытаемся свои замыслы реализовать, но наши усилия имеют мало общего с проектированием себя. Наши уси- 
лия по возобновлению собственной жизни способствуют становлению «распределенного целого», фокусами которого выступают экзистенциальная проблема, наши рациональные действия, погружение на «дно души». Результат становления - поступок и конституирование себя. Конституирование себя - только временная «стоянка», с нее начинается очередной этап эволюции личности, который рано или поздно приводит нас к очередной экзистенциальной проблеме, к невозможности жить по-прежнему.
Анализ этих сложных процессов предполагает «нелинейную логику» в двух основных смыслах. Во-первых, все составляющие распределенного целого и оно само устанавливаются в исследовании и практиковании жизни, которые при этом сами устанавливаются (М.Мамардашвили, А.Пузырей). Во-вторых, наши позиция и подход, как осмысляющего эти процессы, вносит существенный вклад в изучаемый феномен, поэтому так важно их осознавать и артикулировать.

\section{Библиография:}

1. Андреев А.Л. Технонаука // Философия науки: Выпуск 16. М.: ИФ РАН, 2011. С.200-218.

2. Библер В.С. От наукоучения - к логике культуры. М.: Политиздат, 1990. 413 с.

3. Вайнберг С. Мечты об окончательной теории. М.: ЛКИ, 2008. 256 с.

4. Вернадский В.И. Биосфера и ноосфера. - М.: Айрис-пресс, 2003. 576 с.

5. Горохов В.Г. Технонаука Галилео Галилея // Вопросы философии. 2013. №1. С.105-116.

6. Гусейнов А.А. Философия как утопия для культуры // Вестник РФО. 2007. №4. С.38-44.

7. Гусейнов А.А. Философия как этический проект // Вопросы философии. 2014. №5. С.16-26.

8. Касавин И.Т. Проблема и контекст. О природе философской рефлексии // Вопросы философии. 2004. №11. С.19-32.

9. Кутырёв В.А. Естественное и искусственное: борьба миров. Н.Новгород, 1994. 199 с.

10. Миронов В. «Деидеологизация» - новая идеология? (о месте философии в образо-вании) // Высшее образование в России. 2003. №1. С.67-73.

11. Миронов В.В. Философия и Слово // Вопросы философии. 2012. №1. С.14-27.

12. Попкова Н.В. Введение в метафилософию техники. М.: ЛЕНАНД, 2014. 336 с.

13. Попкова Н.В. Философская экология. М.: ЛИБРОКОМ, 2010. 328 с.

14. Розин В.М. Понятия «предмет» и «объект» (методологический анализ) // Вопросы философии. 2010. №12. С.85-96.

15. Розин В.М. Техника и социальность: Философские различения и концепции. М.:ЛИБРОКОМ, 2012. $304 \mathrm{c}$.

16. Розин В.М. Эволюция и метаморфоза понятия «природа» // Философия природы сегодня. М.: ИФ PAH, 2009. С.220-251.

17. Соколов В.В. Философия в исторической перспективе // Вопросы философии. 1995. №2. С.134-147.

18. Степин В.С., Горохов В.Г., Розов М.А. Философия науки и техники. М.: Контакт-альфа, 1995.384 с.

19. Степин В.С. Теоретическое знание. М.: Прогресс-Традиция, 2000. 744 с.

20. Степин В.С. Философия и образы будущего // Вопросы философии. 1994. №6. С.10-21.

21. Хокинг С., Млодинов Л. Высший замысел. М.: Амфора, 2012. 208 с.

\section{References (transliterated):}

1. Andreev A.L. Tekhnonauka // Filosofiya nauki: Vypusk 16. M.: IF RAN, 2011. S.200-218.

2. Bibler V.S. Ot naukoucheniya - k logike kul'tury. M.: Politizdat, 1990. 413 s.

3. Vainberg S. Mechty ob okonchatel'noi teorii. M.: LKI, 2008. 256 s.

4. Vernadskii V.I. Biosfera i noosfera. - M.: Airis-press, 2003. 576 s.

5. Gorokhov V.G. Tekhnonauka Galileo Galileya // Voprosy filosofii. 2013. №1. S.105-116.

6. Guseinov A.A. Filosofiya kak utopiya dlya kul’tury // Vestnik RFO. 2007. №4. S.38-44.

7. Guseinov A.A. Filosofiya kak eticheskii proekt // Voprosy filosofii. 2014. №5. S.16-26.

8. Kasavin I.T. Problema i kontekst. O prirode filosofskoi refleksii // Voprosy filosofii. 2004. №11. S.19-32.

9. Kutyrev V.A. Estestvennoe i iskusstvennoe: bor'ba mirov. N.Novgorod, 1994. 199 s. 


\section{Культура и искусство 2(26) • 2015}

10. Mironov V. «Deideologizatsiya» - novaya ideologiya? (o meste filosofii v obrazo-vanii) // Vysshee obrazovanie v Rossii. 2003. №1. S.67-73.

11. Mironov V.V. Filosofiya i Slovo // Voprosy filosofii. 2012. №1. S.14-27.

12. Popkova N.V. Vvedenie v metafilosofiyu tekhniki. M.: LENAND, 2014. $336 \mathrm{~s}$.

13. Popkova N.V. Filosofskaya ekologiya. M.: LIBROKOM, 2010. $328 \mathrm{s.}$

14. Rozin V.M. Ponyatiya «predmet» i «ob"ekt» (metodologicheskii analiz)// Voprosy filosofii. 2010. №12. S.85-96.

15. Rozin V.M. Tekhnika i sotsial'nost': Filosofskie razlicheniya i kontseptsii. M.:LIBROKOM, 2012. 304 s.

16. Rozin V.M. Evolyutsiya i metamorfoza ponyatiya «priroda» // Filosofiya prirody segodnya. M.: IF RAN, 2009. S.220-251.

17. Sokolov V.V. Filosofiya $\mathrm{v}$ istoricheskoi perspektive // Voprosy filosofii. 1995. №2. S.134-147.

18. Stepin V.S., Gorokhov V.G., Rozov M.A. Filosofiya nauki i tekhniki. M.: Kontakt-al'fa, 1995. 384 s.

19. Stepin V.S. Teoreticheskoe znanie. M.: Progress-Traditsiya, 2000. 744 s.

20. Stepin V.S. Filosofiya i obrazy budushchego // Voprosy filosofii. 1994. №6. S.10-21.

21. Khoking S., Mlodinov L. Vysshii zamysel. M.: Amfora, 2012. 208 s. 